\title{
Intra-speaker Variability in Palatometric Measures of Consonant Articulation
}

Christopher Dromey

Brigham Young University, dromey@byu.edu

Marybeth Sanders

Brigham Young University

Follow this and additional works at: https://scholarsarchive.byu.edu/facpub

Part of the Communication Sciences and Disorders Commons

\section{Original Publication Citation}

Dromey, C. \& Sanders, M. (2009). Intra-speaker variability in palatometric measures of consonant articulation. Journal of Communication Disorders 42, 397-407.

\section{BYU ScholarsArchive Citation}

Dromey, Christopher and Sanders, Marybeth, "Intra-speaker Variability in Palatometric Measures of Consonant Articulation" (2009). Faculty Publications. 1780.

https://scholarsarchive.byu.edu/facpub/1780 
Intra-speaker variability in palatometric measures of consonant articulation

Christopher Dromey, $\mathrm{PhD}^{\mathrm{a}}$

dromey@byu.edu

Marybeth Sanders, $\mathrm{MS}^{\mathrm{a}}$

mbeth1183@hotmail.com

${ }^{\mathrm{a}}$ Brigham Young University

Department of Communication Disorders

133 John Taylor Building

Provo, UT 84602, USA

Corresponding Author

Christopher Dromey

Phone: 801-422-6461

Fax: 801-422-0197 


\begin{abstract}
Electropalatometry is a useful clinical and research tool for measuring linguapalatal contact. The goal of this study was to examine intra-speaker variability in performance. Twenty individuals spoke VCV nonsense words using a schwa in the initial position, the 15 palatal consonants, and three corner vowels, /a/, /i/, /u/. A variability index was created to examine speaker consistency.

Different aspects of articulation (i.e. place, manner, voicing, coarticulation) were compared. Significant differences for variability were found for place of articulation in the /i/ vowel context and for manner of articulation in the /a/ vowel context. Also for the /a/ vowel, significant differences were found between the commonly misarticulated /1/,/r/, and /s/. The data reveal differences in production variability across sounds within an individual, as well as from one speaker to another. This knowledge of typical performance may guide the interpretation of data from disordered speakers in future studies.
\end{abstract}




\section{Introduction}

Dynamic palatometry was developed as a means to understand the articulation of sounds produced with lingual contact against the palate. Several systems have been used in research and therapy over the last two decades. All have involved the fabrication of a plastic pseudopalate, made from the upper dental impression of an individual speaker. In most cases, the electrodes that sense lingual contact with the palate have been manually arranged on the basis of anatomic landmarks on the palate. The individual electrode wires are connected to a computer interface to allow a view of changes in contact over time. The LogoMetrix system also uses a plastic pseudopalate. However, instead of individually placed electrodes, it employs a flexible printed circuit that is glued onto the surface of the pseudopalate. The 118 electrodes are arranged in a grid array with a distance of $3 \mathrm{~mm}$ between the centers. The present investigation used this system to investigate intra-speaker variability in consonant articulation.

In addition to basic research, palatometer systems have been used in the remediation of a number of communication disorders. Several studies have demonstrated the value of palatometry in treating speech deficits associated with hearing impairment (Bernhardt, Gick, Bacsfalvi, \& Ashdown, 2003; Bernhardt, Loyst, Pichora-Fuller, \& Williams, 2000; Crawford, 1995; Fletcher, Dagenais, \& Critz-Crosby, 1991). Others have examined its application with esophageal speakers (Christensen, Fletcher, \& McCutcheon, 1992), developmental articulation/phonological disorders (Dagenais, 1995; Friel, 1998), acquired speech disorders (Goozee, Murdoch, \& Theodoros, 2003), and cleft palate speech (Hardcastle, Gibbon, \& Jones, 1991). The palatometer has been used in therapy for accent reduction (Bright, 1999), and Hardcastle (1972) further suggested its use in foreign language learning and oral physiology research. 
In the context of therapy, it is common for a clinician to demonstrate correct lingual articulation on one part of the computer screen, and for the individual with a speech disorder to watch and then try to imitate this pattern on a second display, based on real-time feedback from the palatometer. This can be an effective means of training correct articulation, as long as it is recognized that motor equivalence and anatomic differences between the two speakers will necessarily result in subtle differences between the two displays, even when both are producing perceptually equivalent sounds. In other words, people make the same sounds in approximately the same way, although the exact placement of the articulators may vary from one person to the next (Fletcher, 1992). This can create problems in the instrumental assessment of disordered speech, since there is no single standard against which to compare potentially abnormal productions.

Because sounds are not made in isolation in everyday communication, the articulation of a speech sound will change as a function of differences in the neighboring phonemes, the tempo, or the stress pattern. Vowel articulation has been found to influence palatal contact patterns. An /i/ has been shown to have a low degree of variability in palate contact when it is articulated with other sounds (Goozee et al., 2003; McAuliffe, Ward, \& Murdoch, 2001). One study by Dagenais and Critz-Crosby (1991) found that for normally hearing participants, velar stops were the only consonants that showed a coarticulatory effect in that their contact moved anteriorly when they were coarticulated with /i/. This is in agreement with the findings of Fletcher (1989). On the other hand, Stone, Faber, Raphael, and Shawker (1992) found that although post-consonant vowels had minimal effect on the consonants, prevocalic consonants had a substantial effect on following vowels. 
Beyond the understandable influence of coarticulation on lingua-palatal contact patterns, there can also be variability in repeated productions of the same sound. The degree of production variability is not uniform from one sound to another (Butcher, 1989). McAuliffe, Ward, and Murdoch (2001) examined the variability of linguapalatal contact patterns and found that $/ 1 /$ had a significantly higher degree of intra-speaker variability than $\mathrm{did} / \mathrm{t} /$ and /s/. Cheng, Murdoch, Goozee, and Scott (2007) considered the effect of age on variability and found that the 6- and 7year old children in their study were significantly more variable in their tongue contact patterns for the velar stop /k/ than the 12- to 17-year olds and adults. With regard to disorders, Dagenais and Critz-Crosby (1991) found that normally hearing participants' tongue-palate contact patterns for consonants were more consistent than those of the speakers with hearing impairment.

Clearly, the particular pattern of contact between the tongue and the palate will vary as a function of numerous influences. In order to make sense of clinical data, it is first necessary to gain an understanding of typical production and its variability. It would be difficult to draw conclusions about a disordered speaker's linguapalatal contact patterns unless we know more about how normal speech is reflected with this technology. Butcher (1989) stated that “...quantitative descriptions of normal dynamic tongue contact patterns...should eventually be possible, firstly, to establish what constitutes the normal range... of speech behavior and, secondly, to measure the degree of deviance from this norm" (p. 47). This is consistent with other researchers' statements concerning the need for data on normal articulation patterns to better judge abnormality (Higgins, Netsell, \& Schulte, 1994; McAuliffe et al., 2001).

The goal of the present study was to quantify the level of intra-speaker articulatory variability in a group of young adults with normal speech. Test stimuli were VCV nonsense words using a schwa in the initial position, 15 alveolar, palatal, and velar consonants medially, 
and three corner vowels, /a/, /i/, /u/ for the final sound. From these palatometric recordings, a variability index was calculated to quantify the degree to which the same electrodes were contacted for repeated tokens of the same sound within speakers. The motivation for this work was based in a desire to understand the normal degree of production variability as a pre-requisite to assessing disordered speech with the same instrumentation.

2. Method

\subsection{Participants}

Ten male $(M=25.9$ years $)$ and 10 female $(M=24.4$ years $)$ speakers took part in the study. They reported no history of speech disorders, jaw problems, hearing impairment, or serious dental abnormalities. Each participant passed a hearing screening bilaterally at 500, 1000, 2000, and $4000 \mathrm{~Hz}$ at $15 \mathrm{~dB}$ HL. Each signed an informed consent document approved by the university IRB.

\subsection{Procedures and Stimuli}

Each participant had an upper dental impression made, from which a plastic palatometer pseudopalate was formed. Before the recording, he or she was engaged in conversation for at least 30 minutes in order to adapt to the presence of the pseudopalate in the mouth.

The recordings were made in an Acoustic Industries sound booth using a head-mounted condenser microphone (AKG C-420) approximately $4 \mathrm{~cm}$ from the mouth. The LogoMetrix palatometer system tracked and recorded the tongue-to-palate contact. 
Data were collected for controlled, isolated word productions. The participants were asked to read aloud a list of VCV nonsense words (see appendix), and then read this list nine more times, as opposed to repeating each word 10 times in a block. The initial vowel for each word was a schwa in order to place the tongue in a neutral position before each consonant production. Fifteen consonants were used: /t, d, k, g, s, z, n, s, t $f, \int, 3,1, r, j, y /$ each in the context of 3 corner vowels, /i, $a, \mathrm{u} /$ in the final position of the VCV nonsense word. An exception was made for $/ \mathrm{y} /$ since it is not used in initial position in the English language. $/ \mathrm{y} /$ was recorded in a VC context using the corner vowels.

\subsection{Data Analysis}

The LogoMetrix software stores data in a series of frames (sampled at $48 \mathrm{~Hz}$ ) that indicate which of the 118 electrodes were touched by the tongue at a given instant. These records were converted to spreadsheet files with the 118 electrodes as columns, and ones or zeros to indicate contact or no contact in each row (i.e., one row for each frame). The maximal contact frame (the instant at which the highest number of electrodes were activated) was used as the representative frame for each consonant production. This was found by summing the number of ones (contact made) across the rows and finding the highest count, because the consonant in the $\mathrm{VCV}$ word was generally associated with the maximum degree of contact between the tongue and the palatometer electrodes. In cases where the maximal contact occurred other than during the consonant - typically when some of the consonants were produced in the context of the high vowels, $/ \mathrm{i} /$ and $/ \mathrm{u} / \mathrm{-}$ the experimenter scanned the frames and chose a representative contact record for the consonant. 
For each speaker for the ten repetitions of each consonant, a contact total was calculated for each electrode. This total represented the number of times across the ten repetitions of the same sound that a given electrode was activated by tongue contact. With the electrode totals calculated, a chart was created to tally the number of ones, twos, threes, and so forth (up to ten) recorded across the ten repetitions for each electrode. For perfectly consistent articulation, a bimodal distribution would be predicted, with a count of either 10 (electrode contacted for every repetition) or 0 (electrode never contacted during any repetition). Any total other than 0 or 10 reflects a degree of inconsistency in the articulatory contact for that sound.

Figure 1 is an example of the data that were used for this process. Variability was quantified for each consonant for each participant. A variability index (VI) was computed as the ratio of the number of totals that were not zeros or 10 s to the total number of sensors (118). This ratio was then multiplied by 100 for convenience. Thus, a higher VI value would indicate that a larger proportion of the sensors were touched intermittently across the ten repetitions of a sound. A low VI would indicate a closer approximation to the bimodal distribution of consistent contact or no contact across the electrodes.

In order to examine the effect of place of articulation on variability, the VIs for $/ \mathrm{t} / \mathrm{and} / \mathrm{k} /$ were compared as were those for $/ \mathrm{d} /$ and $/ \mathrm{g} /$. Both sets of consonants share a manner of production (stops) as well as voicing characteristics. In order to assess the effect of manner of production on variability, the VIs for /d/, /z/, /1/, and /n/ were compared. All of the consonants were articulated at the alveolar ridge and all were voiced, but they differed in manner of production. In order to determine the effects of voicing, the VIs for cognate pairs were compared against each other (i.e. /t/ and /d/, /k/ and /g/, /s/ and /z/, /d / and / $/ \mathrm{f} /$ ). Gender was considered across the consonants to determine whether it had an effect on the variability of production. VIs 
for $/ \mathrm{r} /, / 1 /$, and $/ \mathrm{s} /$ were also considered due to their clinical significance and frequent misarticulation in English speaking children.

3. Results

\subsection{Place of Articulation}

A repeated measures ANOVA revealed a significant difference in VI between $/ \mathrm{t} /$ and $/ \mathrm{k} /$, $F(1,19)=14.242, p=.001$, as well as between $/ \mathrm{d} /$ and $/ \mathrm{g} /, F(1,19)=25.640 p<.001$ in the $/ \mathrm{i} /$ context. These differences are shown in Figure 2. The alveolar sounds were more variable than their velar counterparts when articulated before the /i/ vowel. No significant differences were found for place of articulation in either the $/ a /$ or $/ \mathrm{u} /$ vowel contexts.

\subsection{Manner of Articulation and Voicing}

A comparison of the manner of articulation for the voiced alveolar consonants revealed a significant difference in the /a/ vowel context for VI across /d/, /z/, /n/, and /1/, $F(2.294$, 43.586) $=10.091, p<.001$. Post hoc t-tests showed that $/ \mathrm{da} /$ was more variable than $/ \mathrm{za} /$, $t(19)=3.564, p=.002 ; / \mathrm{na} /$ was more variable than $/ \mathrm{da} /, t(19)=-2.374, p=.028 ; / \mathrm{na} /$ was more variable than $/ \mathrm{la} /, t(19)=3.989, p=.001 ;$ and $/ \mathrm{na} /$ was more variable than $/ \mathrm{za} /, t(19)=-6.369$, $p<.001$. There was not a significant difference in variability between $/ z a /$ and $/ 1 a /, t(19)=-$ $0.755, p=.460$ or between $/ \mathrm{d} a /$ and $/ 1 a / t(19)=1.713, p=.103$. The relative variability for these sounds is shown in Figure 3. No significant effects were found in the $/ \mathrm{i} / \mathrm{or} / \mathrm{u} /$ vowel contexts. No significant effects were found when comparing a voiced consonant with its unvoiced cognate sound. 


\subsection{Common Misarticulations}

There was a significant difference between $/ \mathrm{r} /, / 1 /$, and $/ \mathrm{s} /, F(2,38)=3.569, p=.038$ in the $/ a /$ vowel context. These results were followed-up by a series of $t$ tests which showed that $/ \mathrm{sa} /$ was significantly less variable than $/ \mathrm{ra} /, t(19)=-3.148, p=.005 . / 1 a /$ was not significantly more or less variable than either $/ \mathrm{ra} /$ or $/ \mathrm{sa} /$. See Figure 4. No significant differences were found in the $/ \mathrm{i} /$ or $/ \mathrm{u} /$ vowel contexts.

\subsection{Vowel Effects}

An ANOVA testing the mean variability across all consonants combined, comparing each vowel context, showed a significant effect, $F(2,38)=3.285, p=.048$. Contrast analyses run concurrently with the ANOVA revealed that productions in the /a/ vowel context were significantly less variable than productions in the $/ \mathrm{u} /$ vowel context, $F(1,19)=8.938, p=.008$.

\subsection{Individual Consonant Observations}

Although not statistically significant, the following qualitative observations are offered: /n/ was consistently one of the most variable sounds across the vowel contexts. The liquid, /1/, tended to be more variable in high vowel contexts. The alveolar stops were consistently more variable than the velar stops. The fricatives, $/ \mathrm{s} /, / \mathrm{z} /, / \mathrm{S} /$, and $/ 3 /$ were the least variable in the low

vowel context, $/ a /$, but only the palatal fricatives $/ \mathrm{S} /$, and $/ 3 /$ were the least variable consonants in the $/ \mathrm{u} /$ context. The velar stops, $/ \mathrm{k} /$ and $/ \mathrm{g} /$ were some of the least variable in the high vowel context, but not in the low vowel /a/ context. Figure 5 shows the degree of variability in the production of all of the consonants in the /a/ context. 


\subsection{Speaker Variability}

Correlation coefficients were calculated to examine the association between the mean VI across all consonants for each speaker, comparing the different vowel contexts. Between $/ a /$ and $/ \mathrm{i} /$, the correlation was $r=.757, p<.001$, between $/ \mathrm{i} /$ and $/ \mathrm{u} /, r=.862, p<.001$, and between $/ \mathrm{u} /$ and $/ a /, r=.906, p<.001$. This reveals that a speaker who has high variability for consonants in one vowel context is likely to also have high values for the other vowels. This suggests that some speakers are generally more variable than others. An example of this is seen in Figure 6 . The electrodes are shaded to show variability and percentage of contact. Darker shaded circles reflect a higher average frequency of contact. A white marker would indicate no contact, and a black marker reflects consistent contact across 10 trials. In this figure Speaker 1 shows a high level of consistency across repetitions, compared with Speaker 11 whose productions were much more variable for the same sound.

\section{Discussion}

The purpose of this study was to examine intra-speaker variability in lingua-palatal contact patterns in order to better understand the performance of normal speakers. Different aspects of articulation (i.e. place, manner, voicing, coarticulation) were considered when exploring what might have an effect on speaker variability. Significant findings for variability were found for place of articulation in the /i/ vowel context and for manner of articulation in the /a/ vowel context. Also in the /a/ vowel context, significant differences in variability were found between the commonly misarticulated sounds $/ 1 /, / \mathrm{r} /$, and /s/. Consonants coarticulated with /a/ were found to be significantly less variable than consonants coarticulated with $/ \mathrm{u} /$. Also, speakers 
who were more variable in one vowel context tended to be more variable in other vowel contexts.

\subsection{Place of Articulation}

A possible explanation for $/ \mathrm{k} /$ and $/ \mathrm{g} /$ being less variable than their alveolar counterparts, $/ \mathrm{t} /$ and $/ \mathrm{d} /$, in the $/ \mathrm{i} /$ context may lie in the fact that $/ \mathrm{i} /$ is a high vowel, and coarticulation may account for the differences in variability. The $/ \mathrm{k} /$ and $/ \mathrm{g} /$ are produced in the posterior part of the mouth and with the posterior lateral tongue contact made during /i/, the tongue may be well positioned to make the velar sounds without first making significant articulatory movements. In contrast, for the alveolar sounds the tongue may have moved slightly farther in the mouth after the $/ \mathrm{t} /$ or $/ \mathrm{d} /$ to make the appropriate posterior lateral contacts for the following $/ \mathrm{i} /$.

The alveolar stops $/ \mathrm{t} /$ and $/ \mathrm{d} /$ continued to be more variable than the velars in all of the vowel contexts, although not significantly. This may be due to the part of the tongue being used during sound production. The $/ \mathrm{k} /$ and $/ \mathrm{g} /$ are produced by using the body of the tongue, whereas, the $/ \mathrm{t} /$ and $/ \mathrm{d} /$ are produced using the tongue blade to stabilize and the tongue tip for fine articulation maneuvers. Since the body of the tongue is larger in mass, its contact patterns are more consistent, possibly due to reduced variability in the area it can easily contact. The tongue tip, in contrast, is smaller, more agile and may have a greater potential for variability in the region it can contact during speech.

\subsection{Manner of Articulation}

Of the voiced alveolar consonants /da/,/za/,/na/, and /la/, the nasal /na/ was the most variable. The /n/ may be less precise because a complete anterior vocal tract closure is all that is 
required since the nasal resonance is a primary source of the phonetic differentiation. The exact placement of the tongue to make a /n/ does not affect its intelligibility as much as the other consonants as long as the placement is in the anterior portion of the palate. Also, since nasals, such as $/ \mathrm{n} /$ are low in intensity because of the open velopharyngeal port, the oral constriction is not required to impound as much pressure as other types of consonants. The /d/ was the next most variable, possibly for similar reasons as $/ \mathrm{n} /$. The exact placement of the tongue when producing / $\mathrm{d} /$ is not as vital to its intelligibility as for other consonants, so long as the tongue tip contacts the anterior portion of the palate.

The $/ z /$ and $/ 1 /$ were the least variable of the alveolar consonants. The $/ z /$ is likely less variable because, like its cognate pair/s/, it requires more precision to create a tightly controlled lingual groove for high frequency turbulence generation to be perceived as a correctly articulated sibilant. A slight deviation anteriorly may make an /s/ sound like a lisp and a deviation posteriorly may make it sound like an $/ \mathrm{S} /$. The notion of small lingual movements making important acoustic and/or perceptual changes during consonant production was discussed in detail by Stevens (1989). This contrasts with the production of $/ \mathrm{n} /$, where large variations in lingual movement result in little acoustic or perceptual change.

The /1/ was also less variable. However, the reason for this is unclear. It may be due to the tongue shape and the part of the tongue being used during the articulation of the $/ 1 /$ in the /a/ vowel context. Because the tongue tip is used for $/ 1 /$ in a low vowel context, it may increase the required precision of the tongue-to-palate contact.

The only significant finding for the variability of these consonants was in the /a/ vowel context. This may be because $/ a /$ is a low vowel and the tongue was required to travel greater distances between the consonant contact and the low vowel than with the high vowel. When 
coarticulated with the high vowels, the tongue-to-palate contact increases and that may provide additional stability, which influences the amount of variability a phoneme may have. These coarticulatory 'anchors' are not present with the low vowels and this may contribute to the differences in variability.

\subsection{Common Misarticulations}

The lower variability for $/ \mathrm{sa} /$ than $/ \mathrm{ra} /$ might be attributed to the perceptual impact of minor placement changes, as suggested above; in other words, a misarticulated /s/ is perceptually more noticeable than other sounds because it either sounds disordered if placed too far anteriorly or like $/ \mathrm{S} /$ if placed too far posteriorly. In contrast the $/ \mathrm{r} /$ is traditionally considered to be more variable because there are two possible ways to produce it, either retroflex or back. With the retroflex $/ \mathrm{r} /$, the speaker curls the tongue tip back, whereas with the back $/ \mathrm{r} /$, the speaker bunches and pulls the tongue posteriorly. These two different types of /r/ production would create different contact patterns, although both result in an acceptable $/ \mathrm{r} /$ production. This variability in /r/ production across the speakers may have contributed to the variability in contact found in the data, although there is not clear evidence of this in the data from the present study. The $/ \mathrm{r} /$ productions across speakers, while variable, were made in approximately the same way.

\subsection{Vowel Effects}

The reason why consonants coarticulated with the /a/ vowel may be significantly less variable than consonants coarticulated with the $/ \mathrm{u} /$ vowel is not immediately clear. Both $/ \mathrm{a} / \mathrm{and}$ $/ \mathrm{u} /$ are back vowels, although $/ \mathrm{a} /$ is low and $/ \mathrm{u} /$ is high. Differences in variability may be due to the difference in production height. The other high vowel, /i/, also resulted in more variable 
consonant articulation than $/ a /$, just not significantly so. Another potential explanation is that since the consonant production was proceeded by a schwa and the /a/ vowel is closer in proximity of production of the schwa, the variability of the medial consonant may be reduced. The tongue's movement between the vowels and the consonant may be more precise when the tongue is making more similar sounds on both sides of the consonant. It could also be speculated that the production of the vowel /u/ may vary more and so affect the coarticulation of consonants. The $/ \mathrm{u} /$ can be produced with varying amounts of lip rounding and palatal contact without distorting the sound. This variation may influence the coarticulation effect.

The velar stops, $/ \mathrm{k} /$ and $/ \mathrm{g} /$ were some of the least variable phonemes in the high vowel context, but not with the low /a/ vowel. This increase in variability of velar stops when coarticulated with /a/ was also noted by McAuliffe et al. (2001). When the velar phonemes are coarticulated with high vowels, the tongue-to-palate contact is greater, creating an anchor point for the posterior tongue movement, potentially contributing to greater stability during the sound production.

\subsection{Speaker Variability}

The significant correlations of the mean VI of the speakers across the vowel contexts demonstrates that a person who was more variable in one vowel context was likely to be more variable in other vowel contexts. In other words, some speakers are generally more variable than others. As noted earlier, Figure 6 shows a summary of contact patterns across ten repetitions of /ki/ by two different speakers. Speaker 1 is distinctly less variable than Speaker 11. Perceptually, both were normal speakers. There was no apparent association between a speaker's level of variability and the age, gender, or any oral cavity characteristics of that speaker. The 
physiological data from electropalatometry can reveal interesting differences that do not result in perceptually abnormal speech. It may be that some sounds have a wider range of variability that is not perceptually deviant, but not every speaker utilizes this available range of variability.

\subsection{Individual Consonant Observations}

Consistent with the findings of previous experiments (Dagenais, Lorendo, $\&$ McCutcheon, 1994; Goozee et al., 2003; Hardcastle, Barry, \& Clark, 1987; McAuliffe et al., 2001), the velar sounds / $/ \mathrm{k}$ and /g/ did not always exhibit complete velar closure, particularly in the $/ a /$ and $/ \mathrm{u} /$ vowel contexts. Some researchers have suggested that this incomplete posterior closure is because the point of contact is on the soft palate. In the $/ a /$ and $/ \mathrm{u} /$ vowel contexts, the tongue may be pulled back further in order to coarticulate with the back vowels. If the contact is behind the rows of electrodes on the pseudopalate then the tongue would appear to not make a complete posterior closure (McAuliffe et al., 2001).

Researchers in the field of Parkinson's disease have noted that spirantization, an incomplete stop closure, is not exclusive to hypokinetic dysarthria. They have found that some individuals with normal speech spirantize stops such as /t/ and /k/ fairly frequently (Weismer, 1984). This may also be an explanation for the incomplete posterior closure of velar stops noted in this study.

The speakers tended to make more tongue-to-palate contact for most consonants in the high vowel contexts, particularly with /i/. This was most notable for the posterior phonemes $/ \mathrm{k} /$, $/ \mathrm{g} /$, and $/ \mathrm{y} /$, as well as $/ \mathrm{r} /$. This observation is consistent with the findings of Butcher (1989), Dagenais et al. (1994), and Fletcher (1989). More specifically in this current study, /k/, /g/, and /y/demonstrated more anterior-lateral contact in the high vowel context. This might be expected 
as a function of the contact being pulled forward during the high front production of $/ \mathrm{i} /$. The $/ \mathrm{r} /$ demonstrated increased posterior-medial contact as well as anterior-lateral contact. This increase in contact is likely due to the coarticulation effect of the high vowels, which have more lateral tongue-palate contact, or anchoring for stabilization, than low vowels. Lateral contact required for the production of the high vowels may blend into the preceding consonant, which also requires lateral contact, for a smoother transition to the vowel.

\subsection{Conclusion}

In summary, this study examined the variability in lingual-palatal contact patterns across and within normal speakers in order to give insight into the extent of normal variability. Significant differences in variability were found in connection with the manner of production, place of articulation, and vowel context. These findings increase our understanding of the normal range of variation and may thus help us better understand speakers with abnormal articulation. By knowing the variable area of contact for each phoneme we can better understand what we should expect for clients we treat using palatometer systems.

There are many possible directions for future research to further our knowledge of normal variability. One course that could be taken would be to examine similar data in different contexts. Studying variability of sound production at the sentence or conversation level could provide valuable information on the effect of running speech on phoneme production. A comparison of that type of data with the findings presented in this study would show how speakers alter their articulation to accommodate longer utterances.

Also, future research could explore the effects of different characteristics of unimpaired speakers on the variability of articulation. This study reported that some speakers were found to 
be generally less variable than other speakers. Future work could investigate individual speaker characteristics, such as language background or dialect to determine their potential effect on a person's articulatory contact patterns. Given the relative homogeneity of the present speaker group, it would also be valuable to compare palatometric variability for children versus adults, or adults in different age groups. 
Reference List

Bernhardt, B., Gick, B., Bacsfalvi, P., \& Ashdown, J. (2003). Speech habilitation of hard of hearing adolescents using electropalatography and ultrasound as evaluated by trained listeners. Clinical Linguistics and Phonetics, 17, 199-216.

Bernhardt, B., Loyst, D., Pichora-Fuller, K., \& Williams, R. (2000). Speech production outcomes before and after palatometry for a child with a cochlear implant. Journal of the Academy of Rehabilitative Audiology, 33, 11-37.

Bright, A. (1999). The palatometer as an instrument for accent reduction therapy with three native ESL Spanish speakers. Brigham Young University.

Butcher, A. (1989). Measuring coarticulation and variability in tongue contact patterns. Clinical Linguistics and Phonetics, 3, 39-47.

Cheng, H. Y., Murdoch, B. E., Goozee, J. V., \& Scott, D. (2007). Electropalatographic assessment of tongue-to-palate contact patterns and variability in children, adolescents, and adults. Journal of Speech, Language, and Hearing Research, 50, 375-392.

Christensen, J. M., Fletcher, S. G., \& McCutcheon, M. J. (1992). Esophageal speaker articulation of /s,z/: a dynamic palatometric assessment. Journal of Communication Disorders, 25, $65-76$.

Crawford, R. (1995). Teaching voiced velar stops to profoundly deaf children, using EPG: Two case studies. Clinical Linguistics and Phonetics, 9, 225-269. 
Dagenais, P. A. (1995). Electropalatography in the treatment of articulation/phonological disorders. Journal of Communication Disorders, 28, 303-329.

Dagenais, P. A. \& Critz-Crosby, P. (1991). Consonant lingual-palatal contacts produced by normal-hearing and hearing-impaired children. Journal of Speech and Hearing Research, $34,1423-1435$.

Dagenais, P. A., Lorendo, L. C., \& McCutcheon, M. J. (1994). A study of voicing and context effects upon consonant lingualpalatal contact patterns. Journal of Phonetics, 22, 225-238.

Fletcher, S. G. (1989). Palatometric specification of stop, affricate, and sibilant sounds. Journal of Speech and Hearing Research, 32, 736-748.

Fletcher, S. G. (1992). Articulation: A physiological approach. San Diego: Singular Publishing Group.

Fletcher, S. G., Dagenais, P. A., \& Critz-Crosby, P. (1991). Teaching consonants to profoundly hearing-impaired speakers using palatometry. Journal of Speech and Hearing Research, 34, 929-942.

Friel, S. (1998). When is a $/ \mathrm{k} /$ not a $[\mathrm{k}]$ ? EPG as a diagnostic and therapeutic tool for abnormal velar stops. International Journal of Language and Communication Disorders, 33 Suppl, 439-444.

Goozee, J. V., Murdoch, B. E., \& Theodoros, D. G. (2003). Electropalatographic assessment of tongue-to-palate contacts exhibited in dysarthria following traumatic brain injury: Spatial characteristics. Journal of Medical Speech-Language Pathology, 11, 115-129. 
Hardcastle, W. J. (1972). The use of electropalatography in phonetic research. Phonetica, 25, $197-215$

Hardcastle, W. J., Barry, R. A., \& Clark, C. J. (1987). An instrumental phonetic study of lingual activity in articulation-disordered children. Journal of Speech and Hearing Research, 30, $171-184$

Hardcastle, W. J., Gibbon, F. E., \& Jones, W. (1991). Visual display of tongue-palate contact: electropalatography in the assessment and remediation of speech disorders. British Journal of Disorders of Communication, 26, 41-74.

Higgins, M. B., Netsell, R., \& Schulte, L. (1994). Aerodynamic and electroglottographic measures of normal voice production: intrasubject variability within and across sessions. Journal of Speech and Hearing Research, 37, 38-45.

McAuliffe, M. J., Ward, E. C., \& Murdoch, B. E. (2001). Tongue-to-palate contact patterns and variability of four English consonants in an /i/ vowel environment. Logopedics Phoniatrics Vocology, 26, 165-178.

Stevens, K. N. (1989). On the quantal nature of speech. Journal of Phonetics, 17, 3-45.

Stone, M., Faber, A., Raphael, L. J., \& Shawker, T. H. (1992). Cross-sectional tongue shape and linguopalatal contact patterns in 's', 'sh', and 'l'. Journal of Phonetics, 20, 253-270.

Weismer, G. (1984). Articulatory characteristics of Parkinsonian dysarthria: Segmental and phrase-level timing, spirantization, and glottal-supraglottal coordination. In M.R.McNeil, 
J. C. Rosenbek, \& A. E. Aronson (Eds.), The dysarthrias: Physiology, acoustics, perception, management (pp. 101-130). San Diego: College Hill. 
Appendix

Word List Used During Data Collection

\begin{tabular}{|c|c|c|}
\hline /i/ & $|a|$ & $/ \mathrm{u} /$ \\
\hline atee & atah & atoo \\
\hline adee & adah & adoo \\
\hline akee & akah & akoo \\
\hline agee & agah & agoo \\
\hline asee & asah & asoo \\
\hline azee & azah & azoo \\
\hline anee & anah & anoo \\
\hline ajee & ajah & ajoo \\
\hline achee & achah & achoo \\
\hline ashee & ashah & ashoo \\
\hline ashee (voiced) & ashah (voiced) & ashoo (voiced) \\
\hline alee & alah & aloo \\
\hline aree & arah & aroo \\
\hline ayee & ayah & ayoo \\
\hline eeng & ahno & oong \\
\hline
\end{tabular}


Figure Captions

Figure 1. Example of a bimodal distribution of contact patterns across 10 trials from Speaker 1 for $/ \mathrm{sa} /$. The number of zeros is the count of electrodes that were never contacted across the 10 trials and the number of tens is the count of electrodes that were contact for every trial. Variability Index (VI) is defined as the sum of the electrodes contacted between 1 and 9 times divided by 118, then multiplied by 100 for convenience.

Figure 2. Effect of place of articulation on the mean and standard error of the variability index in the /i/ vowel context.

Figure 3. Effect of manner of production on the mean and standard error of the variability index in the $/ a /$ vowel context.

Figure 4. Comparison of $/ \mathrm{sa} /, / 1 \mathrm{a} /$, and $/ \mathrm{ra} /$ for mean and standard error of the variability index.

Figure 5. Comparison of all consonants for mean and standard error of the variability index in the /a/ vowel context.

Figure 6. Differences in variability among two of the speakers. Each palate display represents articulation of $/ \mathrm{k} /$ in the $/ \mathrm{i} /$ vowel context over 10 repetitions. Darker circles represent more frequent contact across repetitions. 


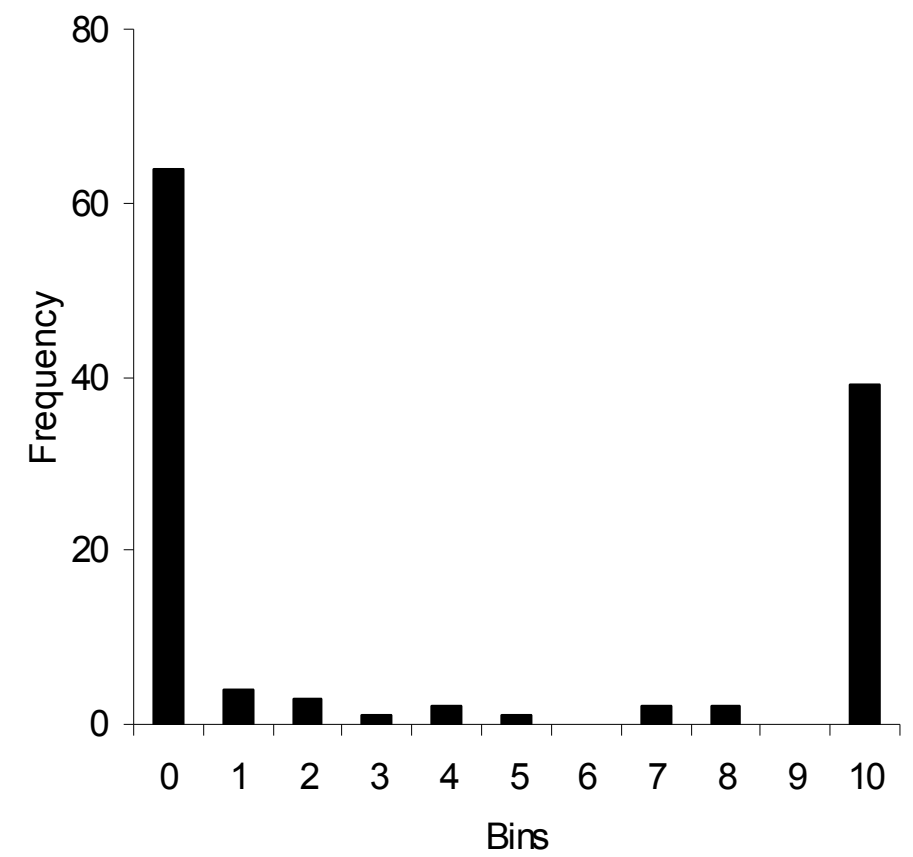

Figure 1 


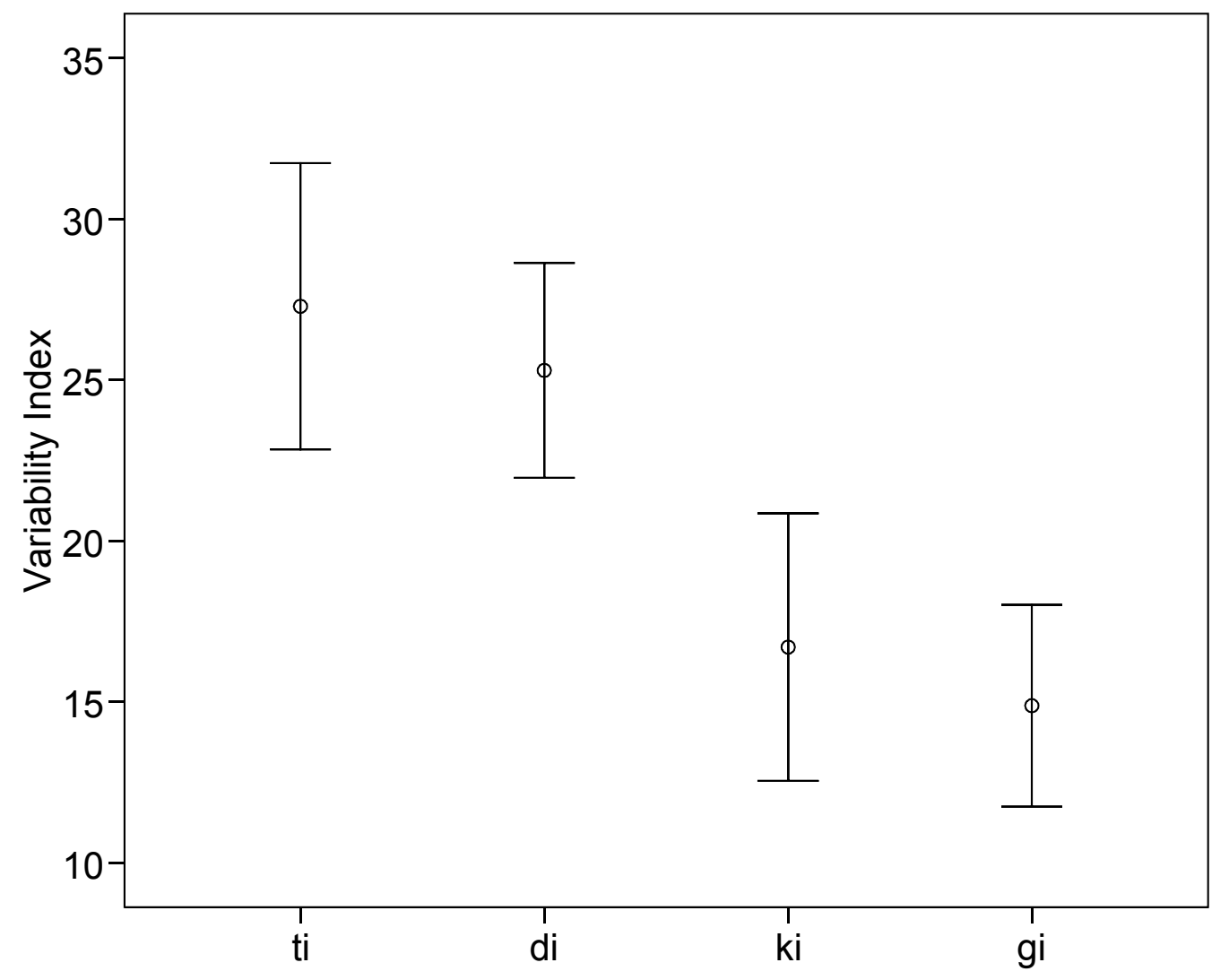

Figure 2 


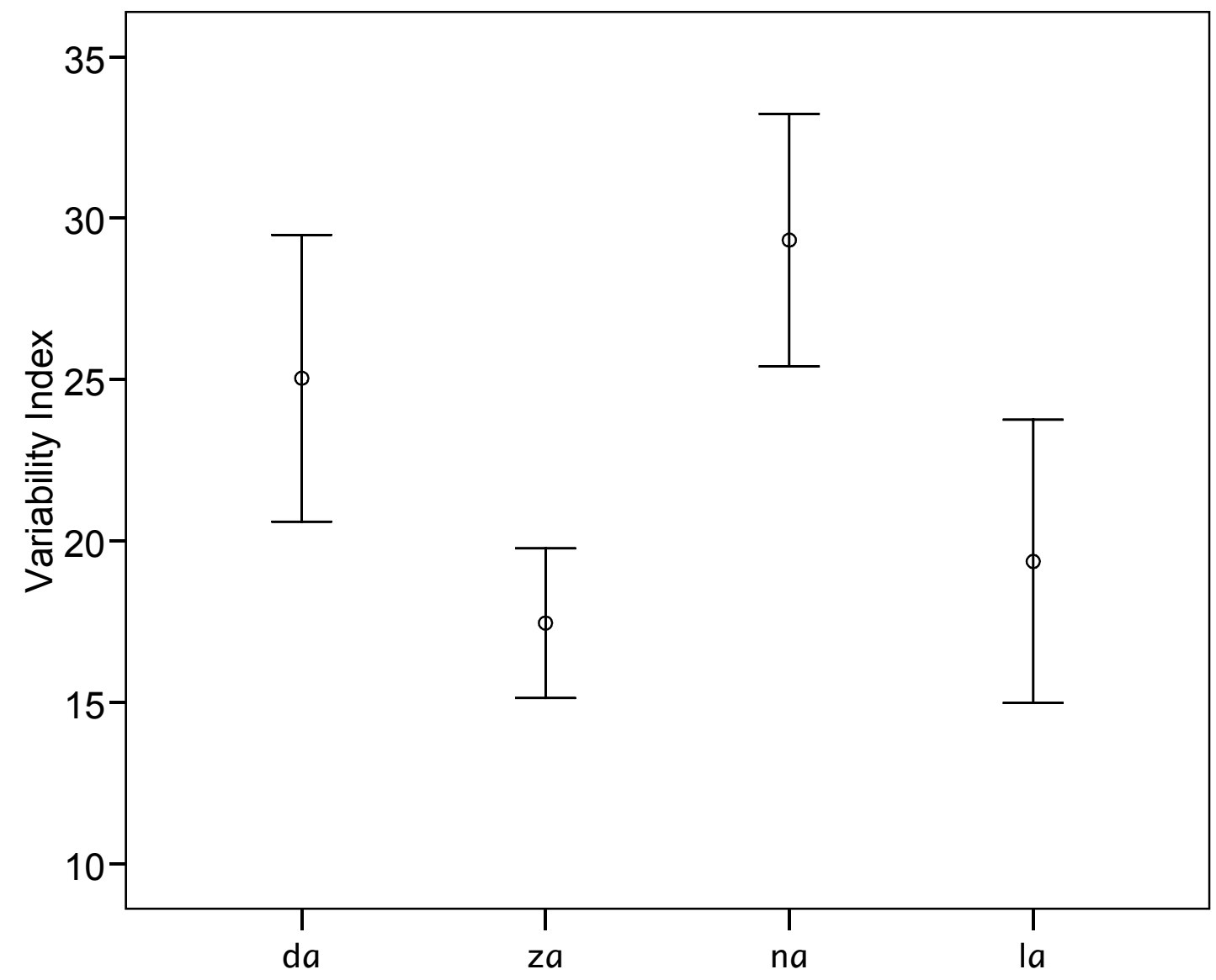

Figure 3 


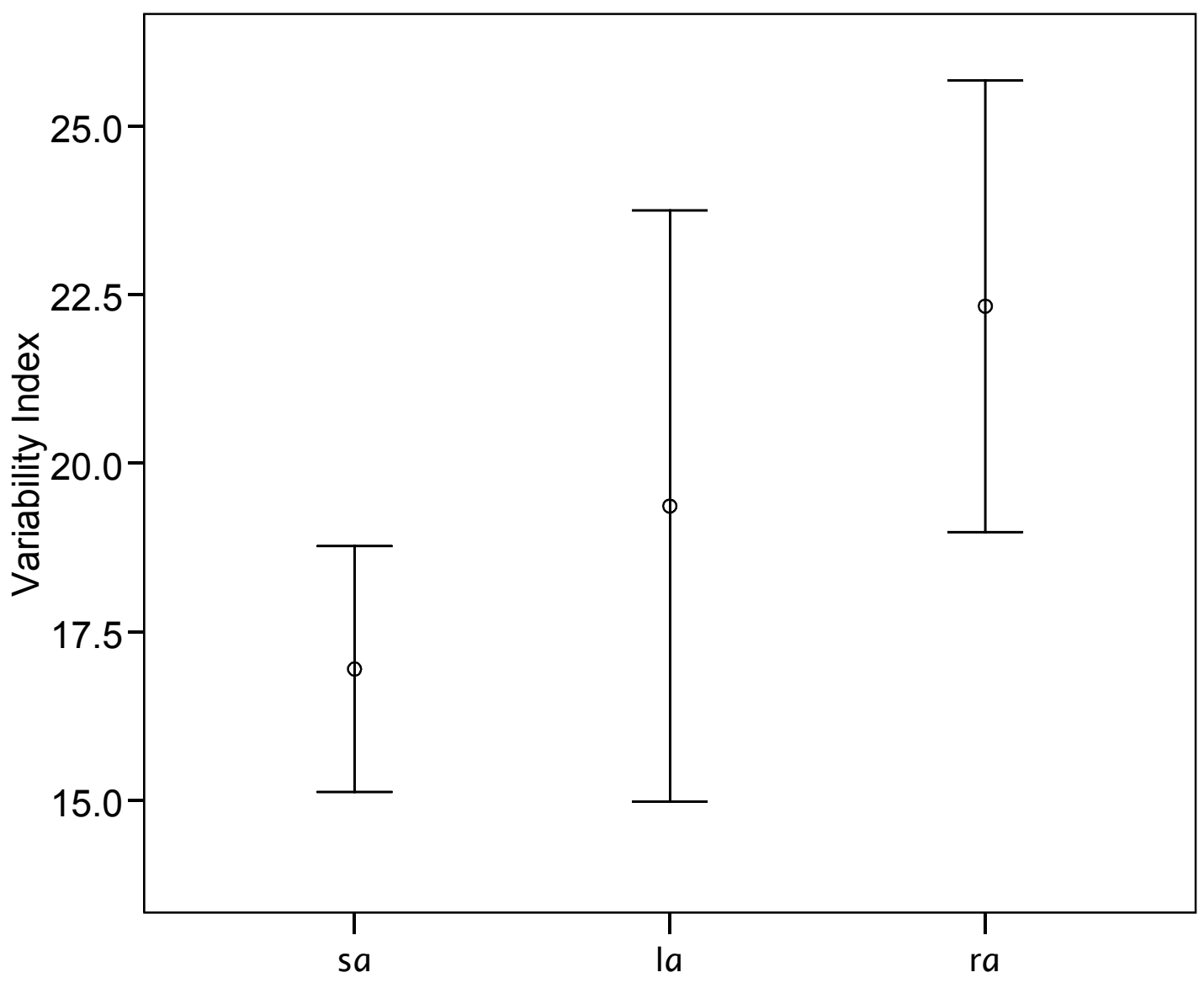

Figure 4 


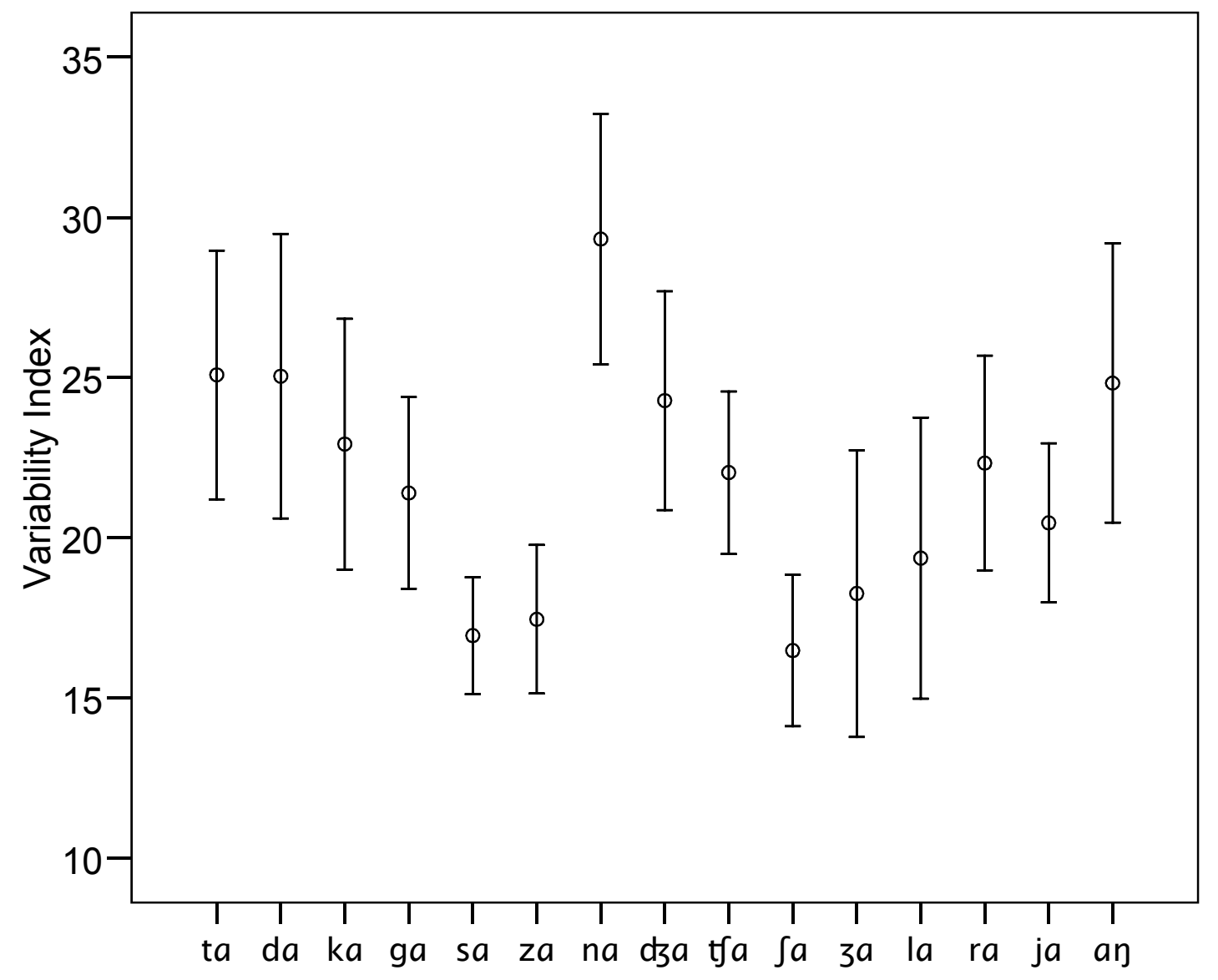

Figure 5 
Speaker 1

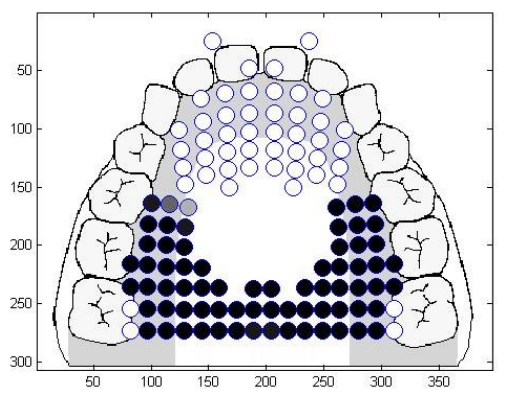

/ki/
Speaker 11

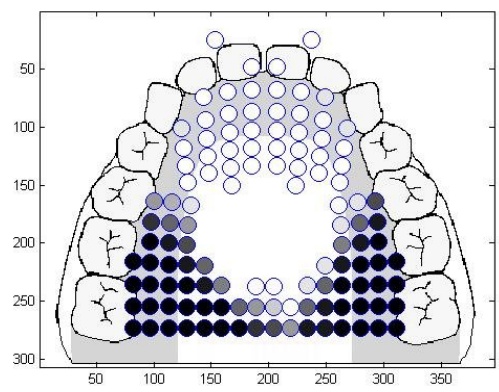

/ki/

Figure 6 
Continuing Education Questions - correct answers underlined

1. Electropalatometry has shown that

a) consonants are articulated the same way by all speakers

b) consonant articulation variability is not influenced by adjacent vowels

c) some consonants are produced more consistently than others across repetitions

d) all of the above

2. The greatest variability in articulation across repetitions is usually for

a) fricatives

b) nasals

c) velar stops

d) corner vowels

3. Voiced consonants articulated at the alveolar ridge

a) have almost identical levels of production variability

b) differ from one another substantially in articulation variability

c) are not influenced by the vowel that follows

d) cannot easily be detected with a palatometer

4. A comparison of voiced/voiceless pairs of stops has shown

a) the voiced stops are more variable

b) that voiceless stops are more variable

c) that voicing only makes a different before high vowels

d) that voicing does not make a difference to variability

5. Individual speakers whose consonant variability is high in one vowel context

a) typically have lower variability for the other vowels

b) typically have high variability in other vowel contexts

c) have unpredictable variability for other vowels

d) have identical variability across all of their consonants 


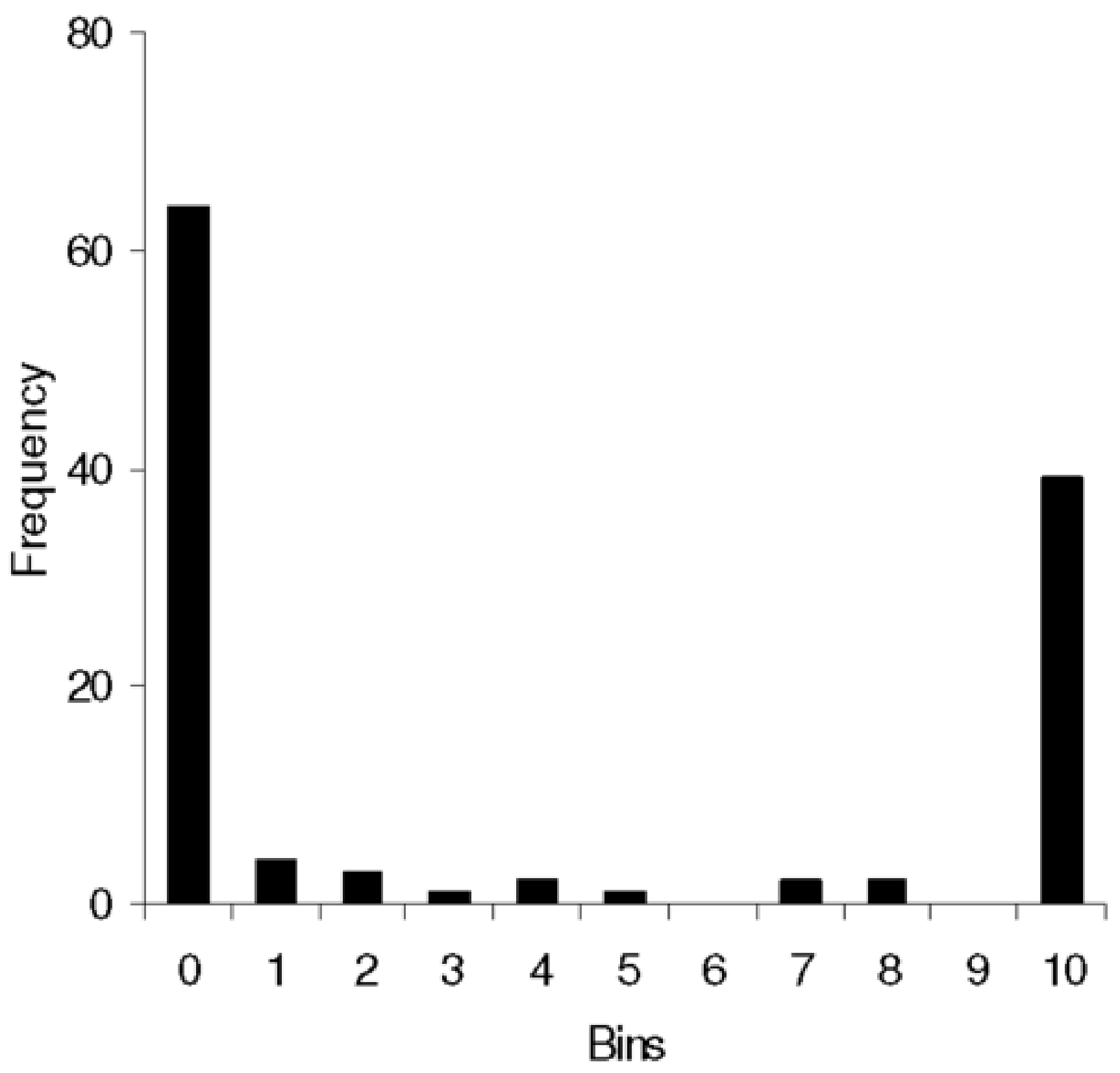




\section{Figure 2}

Click here to download high resolution image

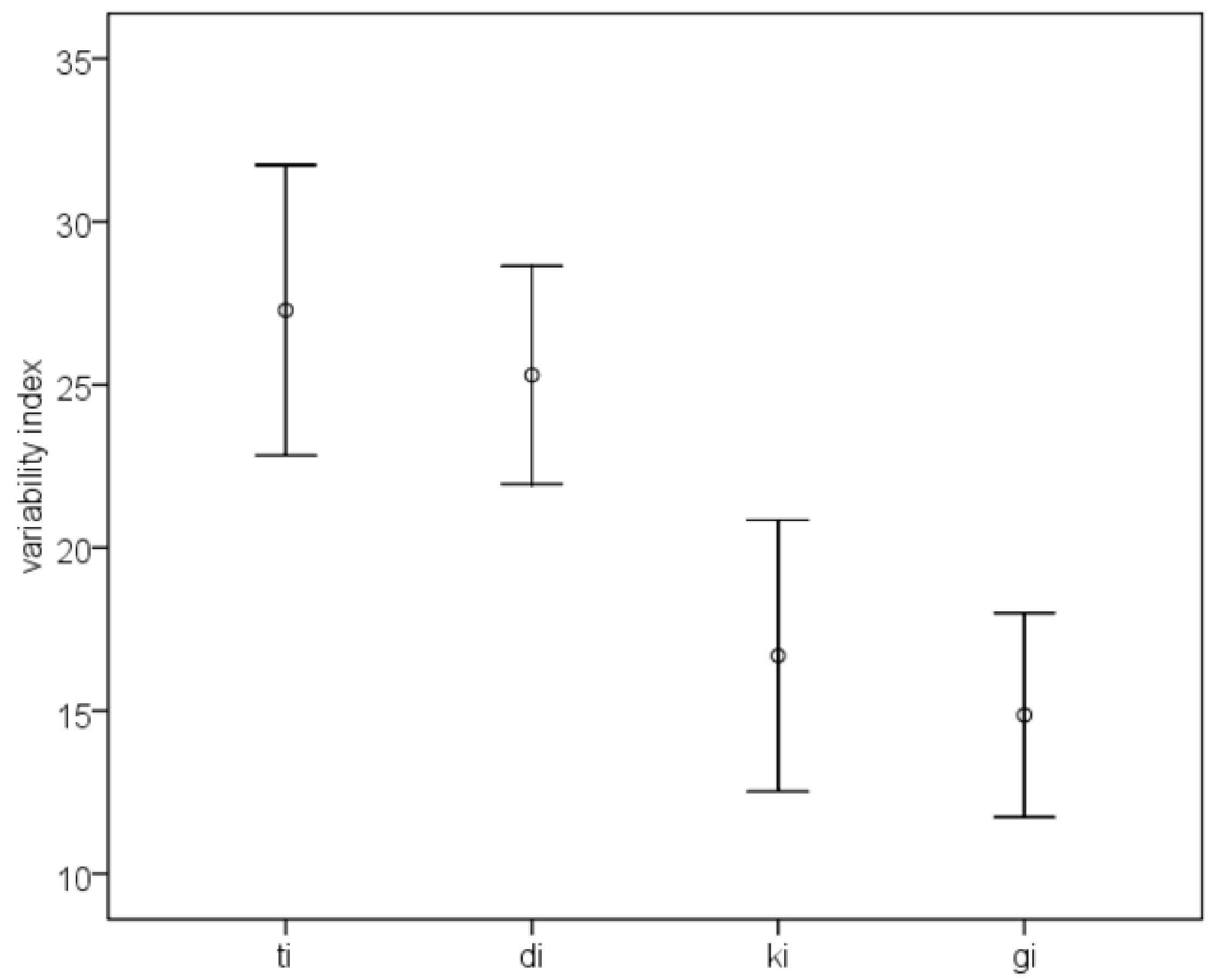




\section{Figure 3}

Click here to download high resolution image

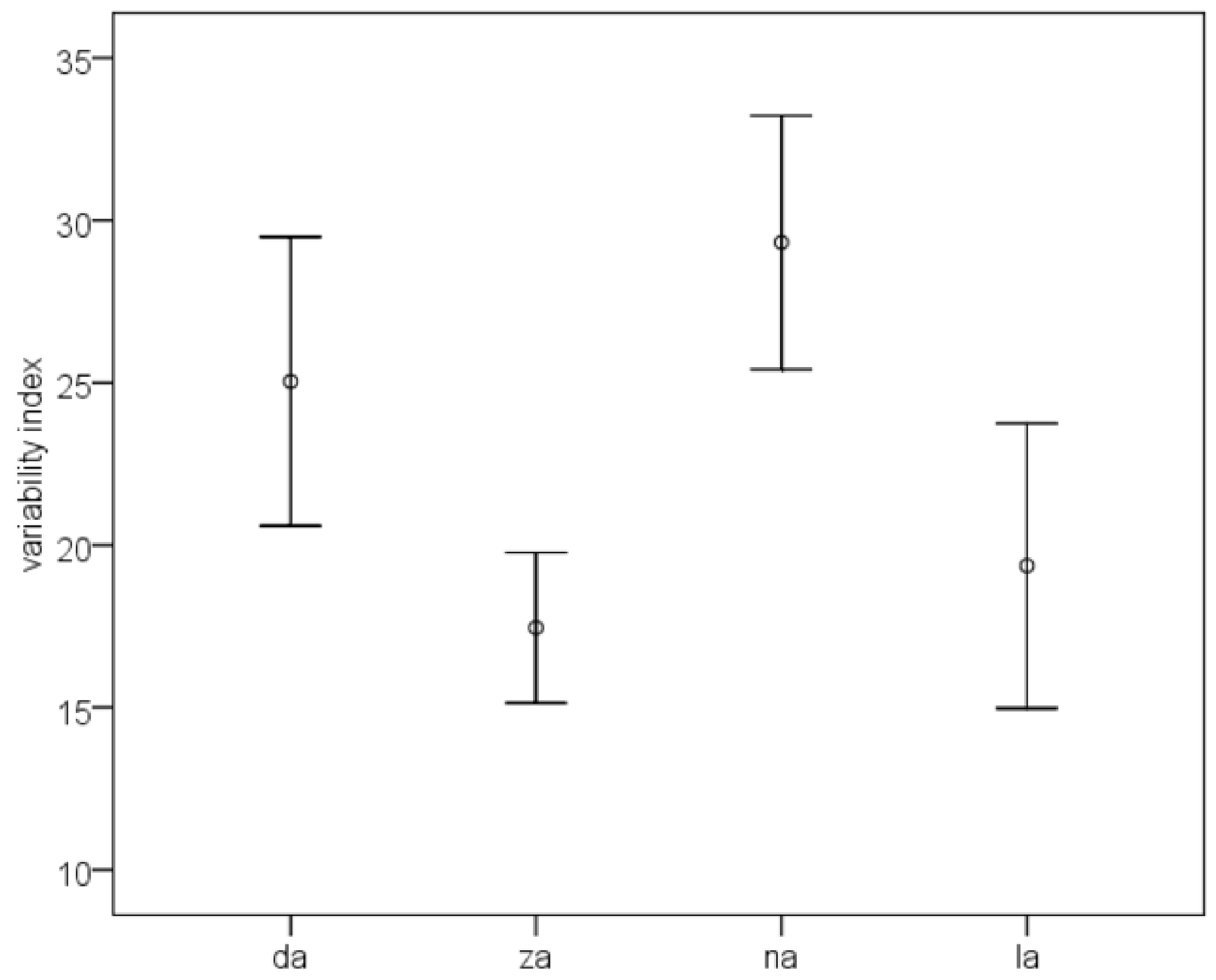


Click here to download high resolution image

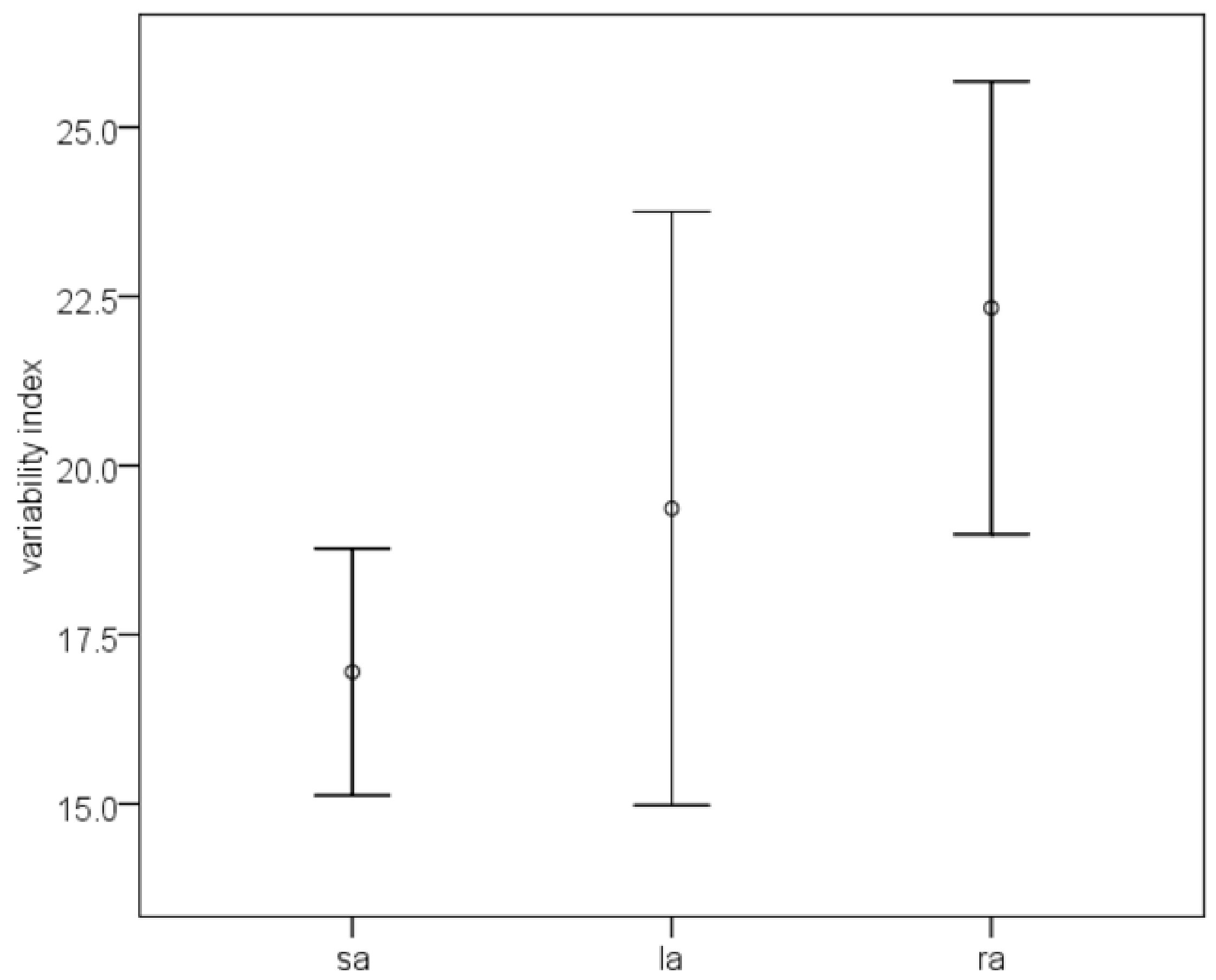




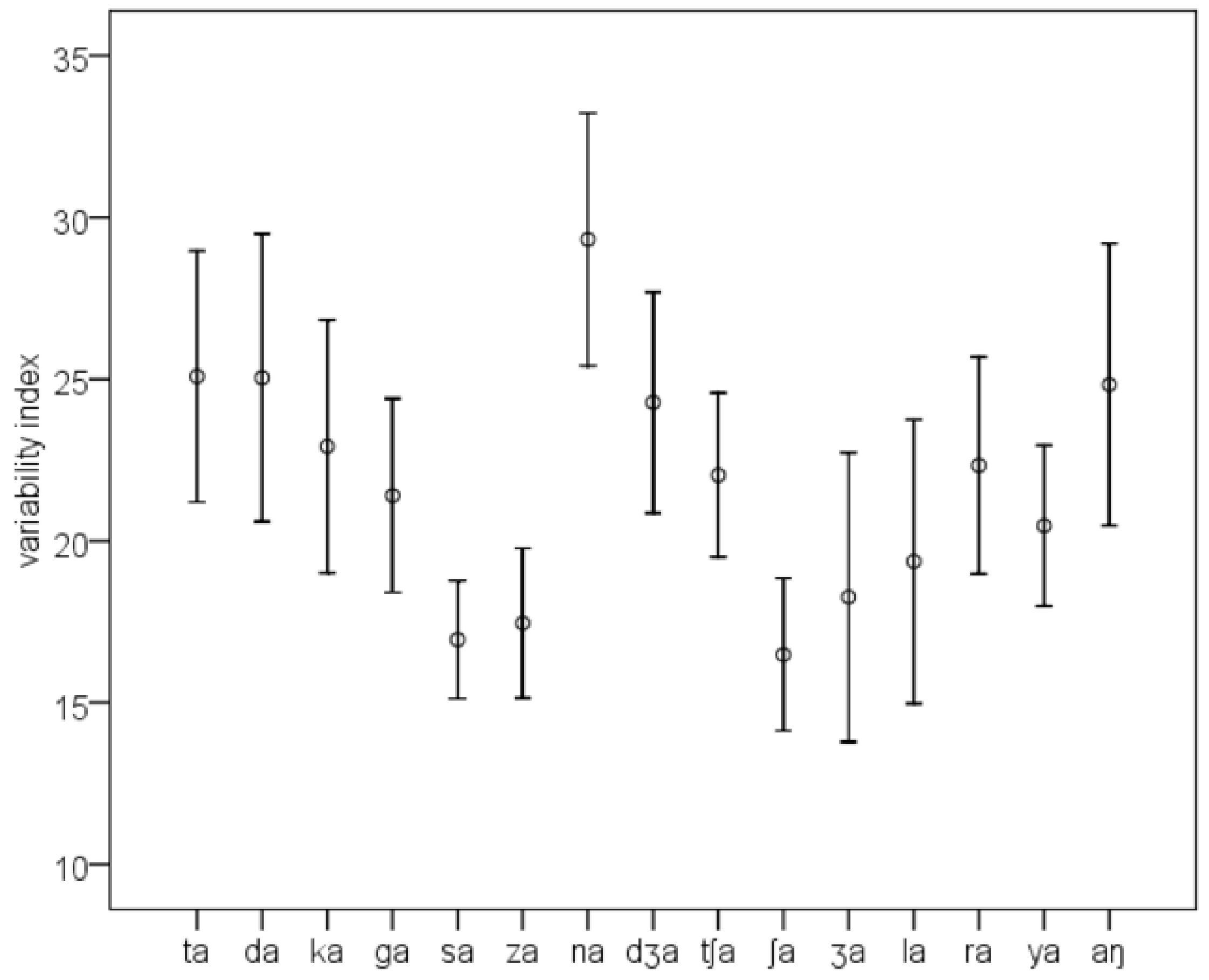




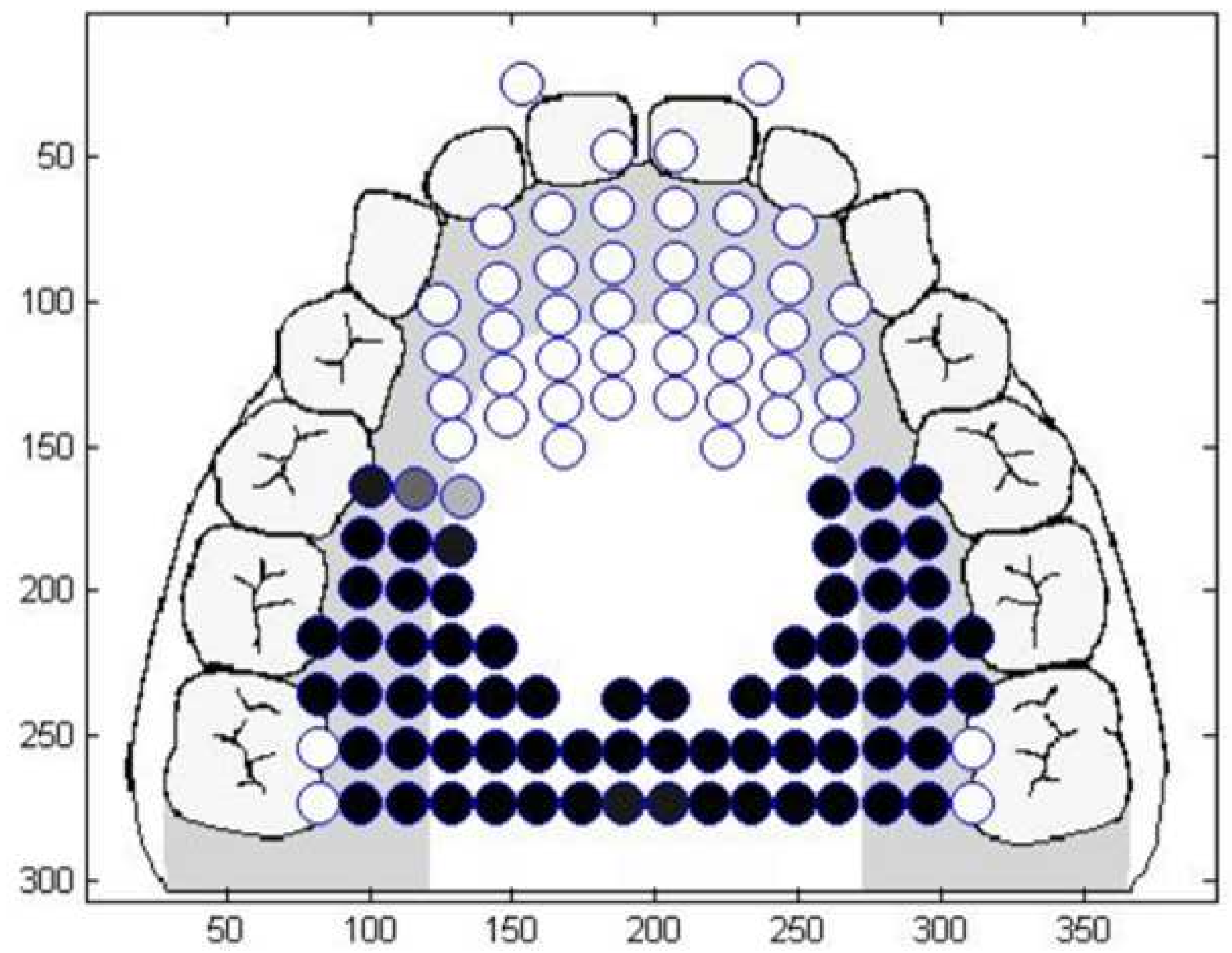




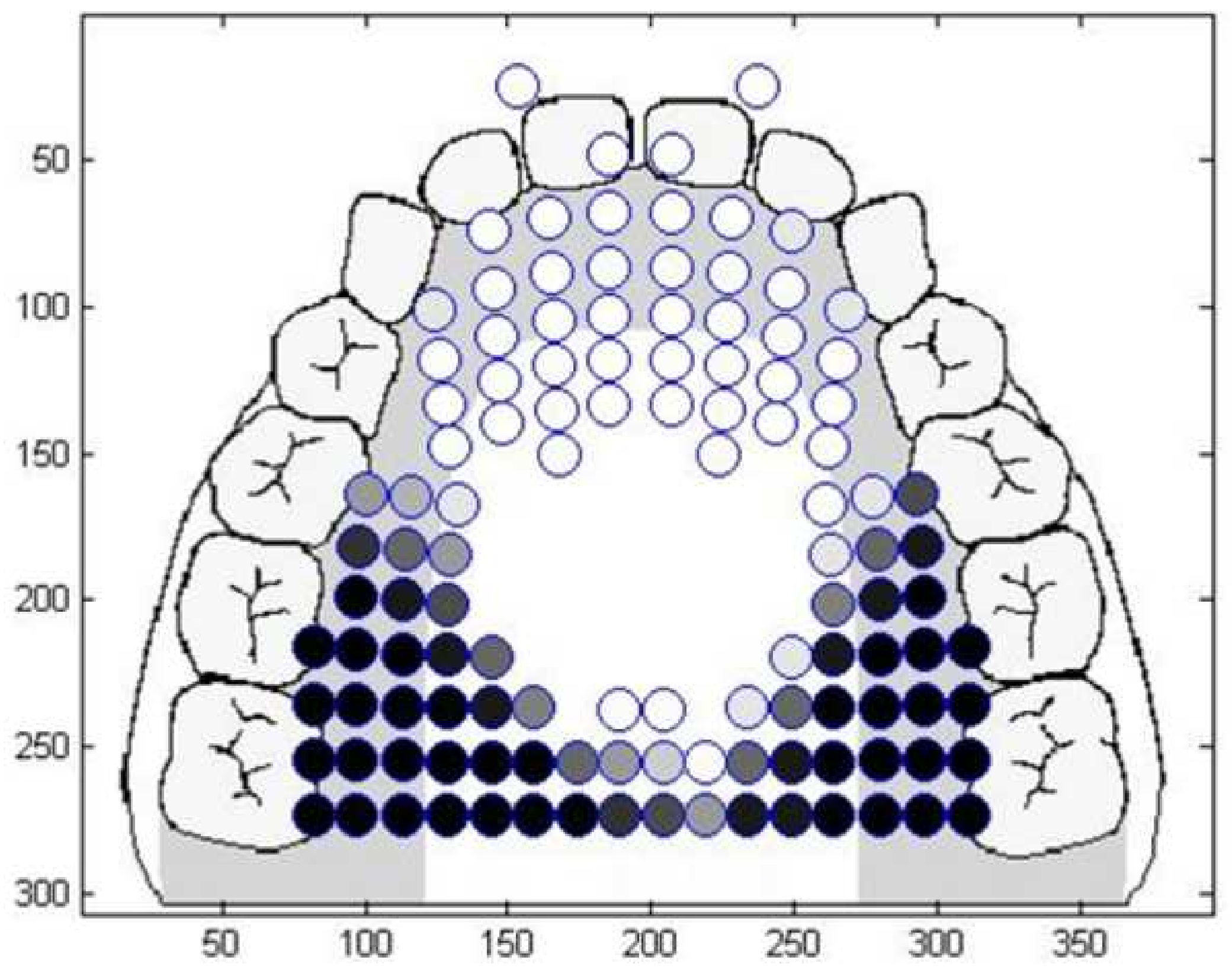

